\title{
Stimulus-response probability and inhibition of return
}

\author{
JASON IVANOFF and RAYMOND M. KLEIN \\ Dalhousie University, Halifax, Nova Scotia, Canada
}

\begin{abstract}
Inhibition of return (IOR) refers to slowed responding to targets at a location previously occupied by an irrelevant cue. Here we explore the interaction between stimulus-response (S-R) probability and IOR effects using go/no-go (Experiment 1) and two-choice discrimination tasks (Experiment 2). In both experiments, the IOR effect was larger for the likely S-R ensemble than for the unlikely one. In the first experiment, there were more false alarms for uncued targets than for cued targets, and this difference was larger for the unlikely S-R ensemble than for the likely one. In the second experiment, the same pattern was observed for incorrect keypress responses. As with voluntary orienting in response to predictive central cues, the results suggest that IOR affects late stages of processing by altering the criteria to respond to targets presented at the cued (previously attended) location.
\end{abstract}

Posner and Cohen (1984) discovered that uninformative peripheral cues have two effects on target processing and that these effects are dissociable in time. When an uninformative peripheral cue is quickly followed by a target (i.e., with cue-target onset asynchronies [CTOAs] less than $250 \mathrm{msec}$ ), responses to targets that appear at the same location as the cue (cued targets) are generally faster than responses to targets that appear at a location different from the location occupied by the cue (uncued targets). This facilitation is thought to be the result of attention being drawn to, and temporarily remaining at, the cued location. In contrast, with relatively long CTOAs, detection responses are slower for targets appearing at the same location as the cue (i.e., cued targets) than they are for targets appearing at uncued locations. This effect is called inhibition of return (IOR), referring to the hypothesis that one effect of the cue is to inhibit attention from returning to a previously occupied location (Posner, Rafal, Choates, \& Vaughn, 1985; see Klein, 2000, and Taylor \& Klein, 1998, for reviews of IOR).

Posner (1980) distinguished between two types of orienting. When attention is attracted to an uninformative peripheral cue, orienting is under exogenous control, referring to the external cause of the shift of attention. Exogenous orienting is often fast and reflexive, at least under some conditions (Folk, Remington, \& Johnston, 1992). In contrast to exogenous orienting, endogenous orienting occurs when a symbolic, central cue predicts

The research was supported by a grant from the McDonnell-Pew Program in Cognitive Neuroscience. We are grateful to Mary Lou Cheal, Eric Ruthruff, and an anonymous reviewer for helpful comments on earlier versions of this manuscript. Part of this research was presented at the 2002 annual meeting of the Psychonomic Society (Kansas City). Correspondence should be addressed to J. Ivanoff, 405 Wilson Hall, 111-21st Ave. S., Department of Psychology, Vanderbilt University, Nashville, TN 37203 (e-mail: ji@or.psychology.dal.ca). the forthcoming location of a target with some degree of certainty. It is referred to as endogenous because the shift of attention is intentionally motivated by expectations, incentives, or instructions.

There is evidence that the effects upon processing of a central cue are different from the immediate effects of a peripheral cue (Briand \& Klein, 1987; Cheal \& Lyon, 1991; Jonides, 1981; Klein, 1994; Lu \& Dosher, 2000; for a review, see Klein \& Shore, 2000), suggesting that it is not merely the controllers but also the natures of the attentional shifts that differ when attention is under endogenous versus exogenous control. One such dissociation is revealed when the two different modes of orienting spatial attention are independently combined with a nonspatial expectancy that is manipulated by varying the frequency of response-relevant stimulus attributes in a block of trials (i.e., S-R probability). One goal of this type of examination is to determine whether the combined effects of cuing and S-R probability results in an additive or an interactive pattern. According to additive factors logic (Sternberg, 1969), two orthogonally manipulated factors that affect the same processing stage will produce an interactive reaction time (RT) pattern, whereas an additive pattern will result when the factors affect different processing stages. Before we consider this type of analysis, we will describe what is currently understood about the S-R probability effect.

It has long been known that likely stimuli are responded to faster, and more accurately, than unlikely stimuli (Fitts \& Peterson, 1964; Hick, 1952; Hyman, 1953; Laming, 1968). The S-R probability effect refers to this performance advantage for the likely S-R ensemble over the unlikely one. One explanation for this effect is that the likely response is prepared or preactivated before the presentation of its associated stimulus (Mattes, Ulrich, \& Miller, 1997, 2002; Miller, 1998). A similar interpretation emphasizes that the criterion for the likely stimulus is closer 
to the initial activation state than the criterion for the unlikely stimulus (Laming, 1968). The implication of this proposal is that the unlikely stimulus is processed more than the likely stimulus. A point of agreement among these ideas is that less evidence is needed to trigger a likely response than an unlikely response.

Klein and Hansen (1990; see also Handy, Green, Klein, \& Mangun, 2001; Kingstone \& Egly, 2001; Klein, 1994) discovered that endogenous cuing effects interact with $\mathrm{S}-\mathrm{R}$ probability effects. The average (weighted according to sample size) RTs and error rates from four studies (Archibald, 1989; Handy et al., 2001; Klein, 1994; Klein \& Hansen, 1990) looking at the interaction between endogenous orienting and S-R probability effects are shown in Figure 1. In these studies, the cue (a central arrow) indicated the likely location of the target. Thus, cued (or "valid") trials were, by definition, more frequent than uncued ("invalid") trials. Responses were generally faster when the cue accurately predicted the location of the target than when it did not and when responses to the likely S-R ensemble were faster than responses to the unlikely $\mathrm{S}-\mathrm{R}$ ensemble. Moreover, the effect of S-R probability on RTs was larger when the targets were presented at the cued location than when targets were presented at the uncued location. An alternative way to describe this interaction is that the effect of endogenous orienting on RT was larger for the likely S-R ensemble than it was for the unlikely $\mathrm{S}-\mathrm{R}$ ensemble. ${ }^{1}$ This suggests that $\mathrm{S}-\mathrm{R}$ probability and endogenous orienting exert their effects on at least one processing stage in common. On the basis of converging evidence from the pattern of results from errors, Klein and Hansen proposed that this common hub was a decision stage. Later, Klein (1994) observed that the exogenous cuing effect is additive with the effect of S-R probability ${ }^{2}$ (see Kingstone \& Egly, 2001, for an extension and replication). According to additive factors logic, this suggests that $\mathrm{S}-\mathrm{R}$ probability and exogenous orienting exert their effects at separate processing stages. This pattern reflects a kind of behavioral single dissociation between endogenous and exogenous orienting. ${ }^{3}$

As noted above, the facilitation from an uninformative peripheral cue is often short-lived and gives way to the longer lasting IOR effect. When the CTOA is longer than $250 \mathrm{msec}$ for detection tasks (Posner \& Cohen, 1984) or longer than $400 \mathrm{msec}$ for discrimination tasks (Lupiáñez, Milán, Tornay, Madrid, \& Tudela, 1997), responses to cued targets are slower than responses to uncued targets. It is generally agreed that the cause of this IOR effect (i.e., slower responses to cued targets than to uncued targets) is related to oculomotor control (Rafal, Calabresi, Brennan, \& Sciolto, 1989), but there is considerable disagreement about the nature of the effect $(s)$ of IOR on processing (Klein, 2000; Taylor \& Klein, 1998). For example, some have argued that IOR only affects attention (Pratt, Kingstone, \& Khoe, 1997), while others have proposed that IOR only affects the response criterion (Klein \& Taylor, 1994).

The purpose of the present study was to shed light on this issue by exploring whether the performance changes associated with IOR are, like endogenous attention, interactive with the effect of S-R probability or, like exogenous attention, are additive with $\mathrm{S}-\mathrm{R}$ probability. On the one hand, if IOR only affects early stages of processing, as Klein (1994) proposed is the case for exogenous shifts of attention, then the effect of S-R probability and the IOR effect will be additive. This is what one

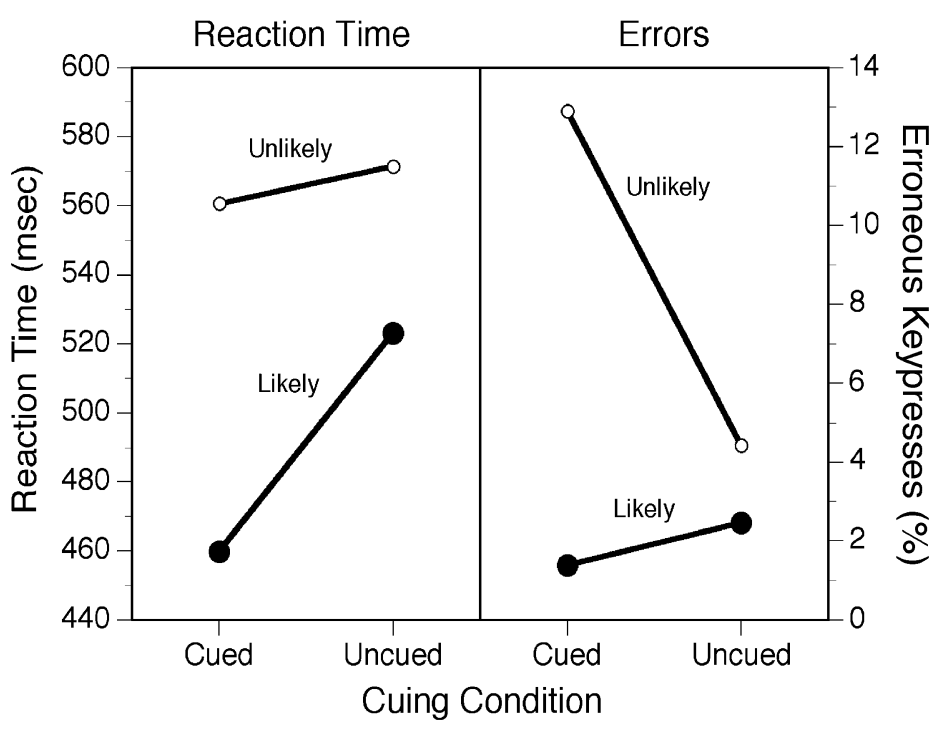

Figure 1. Mean reaction time (in milliseconds) and error rate (\%) as a function of cuing and target likelihood. These results are weighted averages from Archibald (1989), Handy et al. (2001), Klein and Hansen (1990), and Klein (1994). In these experiments, cued ("valid") targets are those for which a central cue correctly predicted the location of the target. Uncued ("invalid") targets are those for which the central cue incorrectly predicted the location of the target. 
might expect given that peripheral cues elicit exogenous shifts of attention and IOR. On the other hand, if IOR involves late, decision-related components (Ivanoff \& Klein, 2001), then the IOR effect should interact with S-R probability. Any interaction suggests that these effects operate on a common stage of processing. However, we can be more specific with our prediction than this. If there is a higher criterion for responding at the cued location (Ivanoff \& Klein, 2001; Klein \& Taylor, 1994), then this translates into a kind of "expectancy" for targets not to appear at the cued location because more evidence is needed to make a response to targets exposed to IOR. The implication of this reverse-expectancy interpretation of IOR is that, when combined with the S-R probability effect, the IOR effect measured with RTs (like the effect of endogenous orienting; Klein \& Hansen, 1990) will be greater for the likely, than for the unlikely, S-R ensemble.

\section{EXPERIMENT 1}

In this experiment, we used a go/no-go task similar to the one used in a previous experiment (Ivanoff \& Klein, 2001) to examine the IOR effect. In this experiment, as in our previous one, there were two stimuli. A single response is to be made to one of the stimuli ("go" target) and withheld from the other ("no-go" target). Ivanoff and Klein (2001) examined performance when the prob- ability of the go target (.67) was higher than the probability of the no-go target (.33). The IOR effect will be examined here as a function of the relative probability of the go (as compared with the no-go) target. In one block, the go target was more likely (.75) to be presented than the no-go target (.25). In another block, the no-go target was more likely (.75) than the go target (.25). Thus, responding in the former block is more likely to occur than it is in the latter block.

\section{Method}

Subjects. Nine undergraduate students from Dalhousie University participated in this experiment for course credit.

Apparatus, Stimuli, and Procedure. An 8500 Macintosh computer running Superlab software was used to to execute the experiment. Subjects were seated approximately $57 \mathrm{~cm}$ from the computer screen. All stimuli were black presented on a white background.

The sequence of events on a trial is illustrated in Figure 2. At the start of every trial, the screen was blank for $450 \mathrm{msec}$. Following this, three squares, each measuring $1.5^{\circ} \times 1.5^{\circ}$ (visual angle), were presented horizontally. The distance from the outside of the central placeholder to the inside of the lateral placeholders was $6.2^{\circ}$. Inside the central placeholder was a hollow black fixation circle measuring $0.8^{\circ}$ in diameter. The thickness of the fixation point was $0.2^{\circ}$. This display remained present for the remainder of the trial. Then, $750 \mathrm{msec}$ following the onset of the placeholder display, a cue was presented within the left or right placeholder for $120 \mathrm{msec}$ with equal frequency. The cue was a circle, $1.5^{\circ}$ in diameter, with a "+" inside of it. Following removal of the cue, the placeholders were

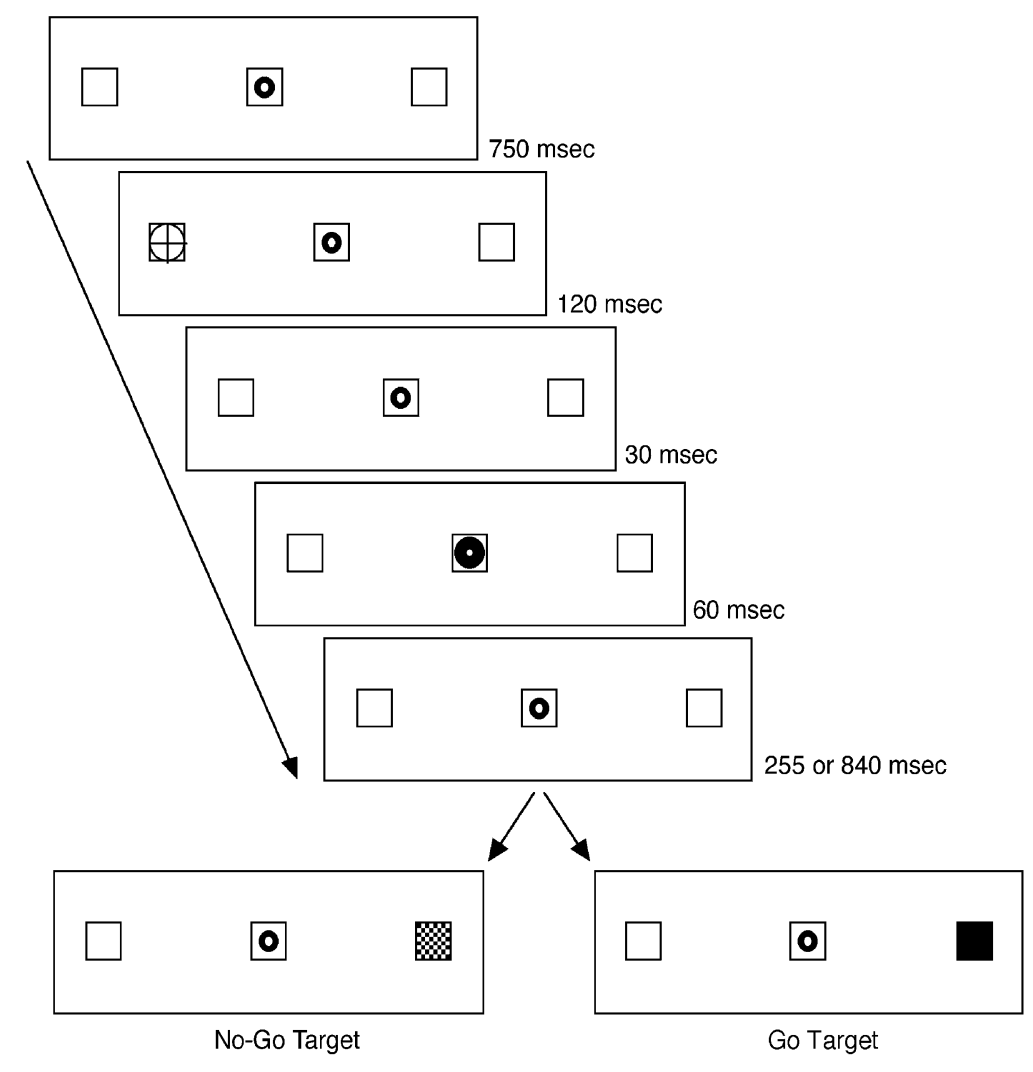

Figure 2. A graphic depiction of trial events (not to scale). Shown is an uncued trial. Responses were to be executed only when a go target is presented. See text for full details. 
shown alone for $30 \mathrm{msec}$. The fixation circle briefly $(60 \mathrm{msec})$ enlarged to $1.2^{\circ}$ by doubling its thickness. Then, 255 or $840 \mathrm{msec}$ following this cue back to fixation, a target stimulus appeared to the left or right. Therefore, the CTOA was either 465 or 1,050 $\mathrm{msec}$ (see Ivanoff \& Klein, 2001). These CTOAs were chosen to cover the range where one would expect to observe IOR. The targets were a black square or a checkerboard square $(10 \times 10$ grid of black and white) each measuring $1.5^{\circ}$, presented for $750 \mathrm{msec}$ or until a response was made.

The cue was uninformative about the location of the target (i.e., cue validity was $50 \%$ ). Subjects were instructed that the cue was irrelevant and that upon the appearance of the go target (black square), they were to make a response as quickly as possible with the index finger of their right hand on the " $n$ " key of an ADB keyboard. If the no-go target appeared (i.e., the checkerboard target), they were instructed to withhold responding. Response speed and accuracy were equally stressed. There were two blocks of trials. In one of the blocks, the go target appeared $75 \%$ of the time (likely target) and the no-go appeared $25 \%$ of the time. In the other block, this was reversed and the go target was unlikely (25\%). RTs to go targets were recorded, as were false alarms (responses to the no-go target). The order of blocks was approximately counterbalanced between subjects. In each of the two blocks, there were 320 trials.

\section{Results and Discussion}

RTs were trimmed so that those faster than $150 \mathrm{msec}$ were removed from the analysis. This eliminated only one trial. When considering the results from this experiment, we must keep in mind that stimulus probability has a straightforward meaning with regard to responses to targets (the targets are either likely or unlikely). Figure 3 shows the mean RTs and mean false alarm rates for each condition. Because there were no significant inter- actions involving CTOA, the results from the 465- and 1,050-msec CTOAs were collapsed in Figure 3. The mean false alarm rates and mean RTs for each cell in the design are provided in the Appendix. A repeated measures (CTOA, go target probability, and cue condition) analysis of variance (ANOVA) on the RTs revealed that all three main effects were significant: CTOA $[F(1,8)=17.03, p<.005]$, go target likelihood $[F(1,8)=10.70, p<.05]$, and cuing $[F(1,8)=53.43, p<.0001]$. Responses were $15 \mathrm{msec}$ faster with the 1,050-msec CTOA than they were with the 465-msec CTOA; 28 msec faster when the go target was likely than when it was unlikely; and $29 \mathrm{msec}$ slower for cued than for uncued targets (IOR). The interaction between go target probability and cuing was significant $[F(1,8)=19.49, p<.005]$ : The IOR effect was nearly twice as large when go-target was likely $(38 \mathrm{msec})$ than when it was unlikely $(20 \mathrm{msec})$.

When the same analysis was performed on the false alarm rates, the main effects of go target probability $[F(1,8)=9.81, p<.01]$ and cuing $[F(1,8)=9.35, p<$ $.05]$ were significant. There were more false alarms when the go target was likely $(M=8.19 \%$; i.e., the percentage of responses to unlikely no-go targets) than when it was unlikely $(M=1.11 \%$; i.e., percentage of responses to likely no-go targets), and there were more false alarms to uncued targets $(M=7.50 \%)$ than to cued targets $(M=$ $1.81 \%)$. In addition, the interaction between go-target probability and cuing $[F(1,8)=8.27, p<.05]$ was significant. The difference between cued and uncued false alarm rates was larger when the go target was likely (and

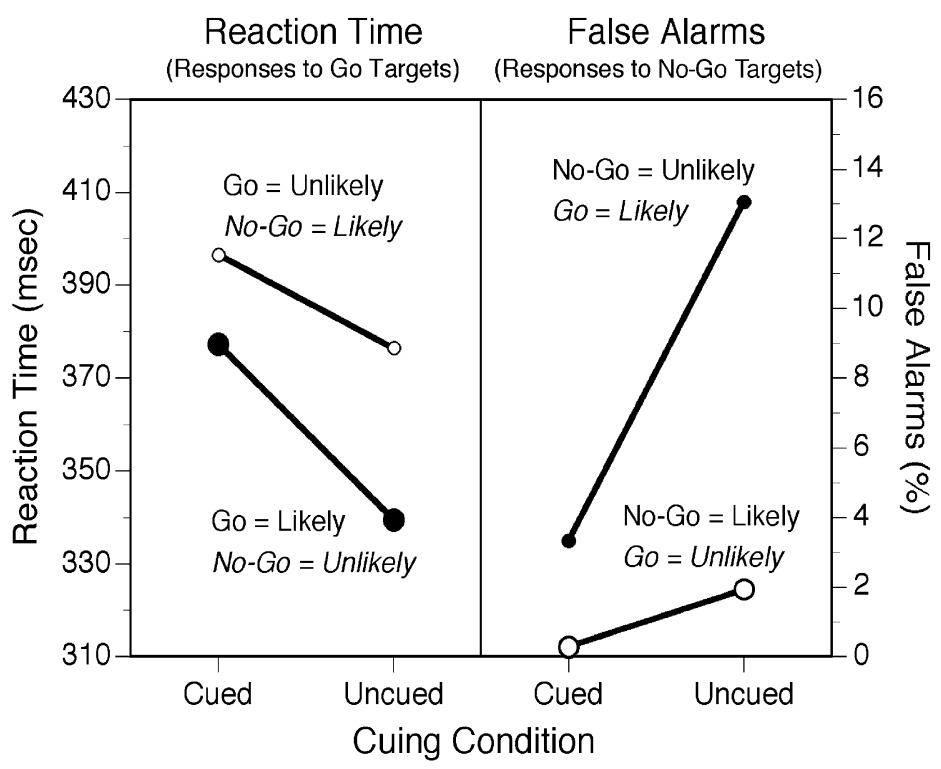

Figure 3. Mean reaction time (in milliseconds) and false alarm rate (\%) as a function of cuing and target likelihood. Data collected from the block when the go target was likely (Go = Likely) are plotted as solid circles, and data from the block when the go target was unlikely (Go $=$ Unlikely) are plotted as unfilled circles. For each data point, the likelihood of the stimuli to which the subject was responding is conveyed by the size of the circle (small for unlikely targets and large for likely targets). The italicized text refers to the alternative targets within the block. 
the no-go target was unlikely; uncued false alarm \% cued false alarm $\% ; M=9.72 \%)$ than when go target was unlikely $(M=1.67 \%)$.

As in Ivanoff and Klein (2001), false alarms (responses to no-go targets) were less frequent when no-go targets were presented at the cued location than when they were presented at the uncued location. This pattern supports the proposal (Klein \& Taylor, 1994) that IOR can be generated by a relative increase in the criterion for responding to cued targets. Furthermore, the IOR effect-measured with false alarms and RT - interacted with S-R probability. This interaction between the $\mathrm{S}-\mathrm{R}$ probability effect and IOR is very similar to that observed with endogenous cuing (Figure 1) and is very much unlike the additive pattern observed with exogenous cuing.

In previous experiments (Handy et al., 2001; Kingstone \& Egly, 2001; Klein, 1994; Klein \& Hansen, 1990), the interaction between the locus of attention (endogenous and exogenous forms) and S-R probability was explored in a choice-RT task wherein responses were made to all stimuli and the likely and unlikely S-R ensembles were mixed within the same block of trials. The interaction we have discovered (Figure 3 ) between IOR and S-R probability was obtained using a go/no-go task in which the probability of responding (on go trials) was varied between blocks. In Experiment 2, we will seek to replicate this interaction using a choice-RT task. Failure to obtain the interaction will suggest that it was an incidental feature of the go/no-go task and its consequent blocked manipulation of probability. On the other hand, replication will demonstrate that the interaction we have obtained between S-R probability and IOR (the aftermath of orienting) is robust and akin to the interaction reported by Klein (1994; Klein \& Hansen, 1990) using endogenous orienting.

\section{EXPERIMENT 2}

In this experiment, the likely and unlikely targets each have an associated response within the same block. A choice-RT task was used in which one stimulus called for one particular response and the other stimulus called for a different response.

\section{Method}

Subjects. Nineteen subjects from Dalhousie University participated in the experiment as part of a 3rd-year course.

Apparatus, Stimuli, and Procedure. Unless otherwise noted, the methodology was the same as that in the first experiment. Subjects were tested simultaneously in a psychology lab on iMAC computers. The peripheral cue was presented for $60 \mathrm{msec}$ and, $15 \mathrm{msec}$ following the removal of the cue, the central cue (the increase in the fixation circle) was presented for $60 \mathrm{msec}$. The target was then presented 15,315 , or $900 \mathrm{msec}$ later for CTOAs of 150,465 , and 1,050 msec. The likelihood of the black square target was $75 \%$ (i.e., likely target) and the likelihood of the checkerboard targets was $25 \%$ (unlikely target). Responses were made with the right and left index fingers, on the " 8 " and " 2 " keys of the iMAC's number pad, to the black square and checkerboard targets. Subjects were instructed to respond quickly and accurately to the target. In total, there were 384 trials.

\section{Results and Discussion}

RTs less than $200 \mathrm{msec}$ and greater than $1,000 \mathrm{msec}$ were removed from the analysis. These criteria resulted in the exclusion of less than $1 \%$ of all trials. Mean RTs and errors are shown in Figure 4 as a function of cuing and target likelihood. Again, all three CTOAs have been collapsed in Figure 4 because the three-way interaction between cuing, target likelihood, and CTOA was not significant $[F(1,18)=0.82, p>.4]$. The mean RTs and the mean percentage of incorrect responses are provided in the Appendix as a function of CTOA, target likelihood, and cuing. A repeated measures (CTOA, target likelihood, and cue condition) ANOVA revealed that all three main effects were significant: CTOA $[F(2,36)=97.21$, $p<.0001]$, target likelihood $[F(1,18)=96.29, p<$ $.0001]$, and cuing $[F(1,18)=31.19, p<.0001]$. RTs declined with increasing CTOA, were $70 \mathrm{msec}$ faster to the likely than to the unlikely target, and were $19 \mathrm{msec}$ slower to cued than to uncued targets. The interaction between cuing and CTOA was not significant, indicating that the IOR effect was obtained at every CTOA. In some respects, it is surprising that we obtained an IOR effect at the early CTOA (150 msec), where facilitative effects are normally observed (Lupiáñez et al., 1997). Our use of the second, central, cue is probably responsible for the manifestation of early IOR because it would have removed attention from the periphery (MacPherson, Klein, \& Moore, 2003) before the target appeared.

Target likelihood interacted with CTOA $[F(2,36)=$ $6.10, p<.01]$, reflecting the fact that the S-R probability effect was smaller at the 150-msec CTOA (unlikely likely: $57 \mathrm{msec}$ ) than it was at the longer intervals [ $465 \mathrm{msec}$ : $78 \mathrm{msec} ; 1,050 \mathrm{msec}: 74 \mathrm{msec}]$. Most importantly, target likelihood interacted with cuing $[F(1,36)=8.83, p<.01]$. The IOR effect was about twice as large for the likely stimulus $(M=26 \mathrm{msec})$ as for the unlikely $\mathrm{S}-\mathrm{R}$ ensemble $(M=12 \mathrm{msec})$.

The percentage of errors was entered into the same analysis as that performed on the RTs. There were no significant effects involving CTOA, so the results from all three CTOAs were collapsed (Figure 4). Note that an error to the likely target means that the unlikely response was made and that an error to the unlikely target means that the likely response was made. The main effect of target likelihood was significant $[F(1,18)=31.94, p<$ .0001 ], reflecting the fact that there were $9.10 \%$ more errors when the unlikely target was presented than when the likely target was presented. Target likelihood significantly interacted with cuing $[F(1,18)=6.50, p<.05]$. When the likely stimulus was presented, there were few errors $(M=1.86 \%)$, and the difference between errors for targets at the cued and uncued locations did not differ. However, when the unlikely stimulus was presented, there were significantly $[t(18)=2.31, p<.05]$ more errors for targets at the uncued location $(M=13.60 \%)$ than for targets at the cued location $(M=8.33 \%)$. These results replicate those of Experiment 1 and extend the interactive pattern between S-R probability and IOR to a 


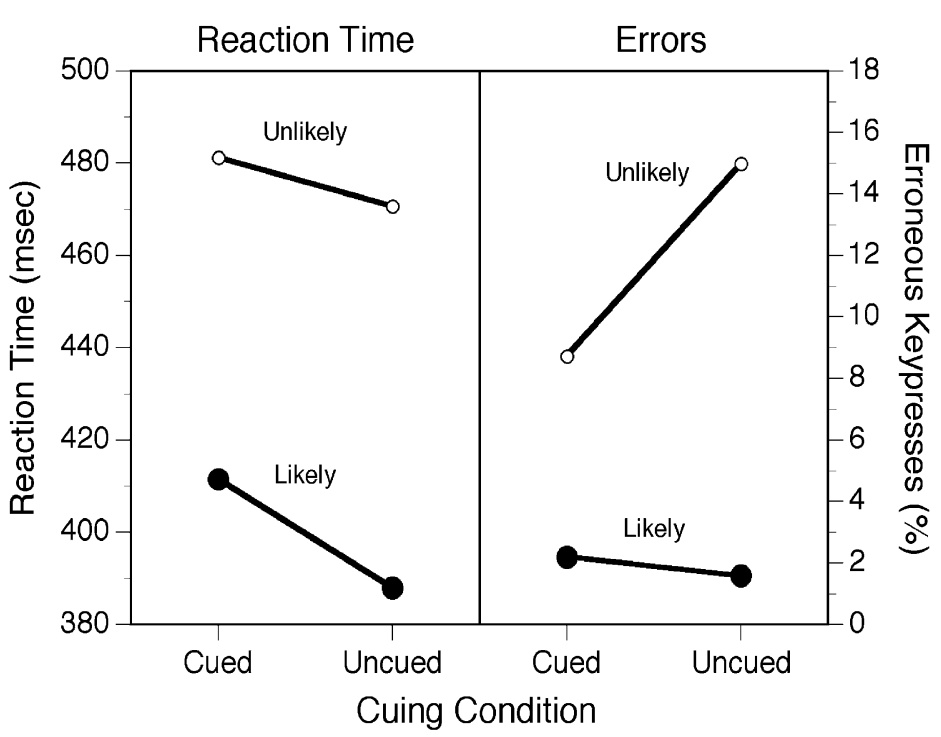

Figure 4. Mean reaction time (in milliseconds) and error (erroneous keypresses, \%) in Experiment 2 as a function of cuing and target likelihood. For each data point, the likelihood of the target to which the subject was responding is conveyed by the presence/absence of fill and size of the circle (small, unfilled circles for unlikely targets and large, filled circles for likely targets).

choice-RT task. The evidence suggesting an effect of IOR on late response stages of processing is thus robust and not limited to go/no-go tasks.

\section{GENERAL DISCUSSION}

In two experiments, we demonstrated that the IOR effect, measured with RTs, was larger when the S-R ensemble was likely than when it was unlikely. Additionally, the pattern of results with errors (false alarms in Experiment 1 and incorrect keypresses in Experiment 2) generally indicated that there were more erroneous responses to uncued targets than to cued targets. This effect was more pronounced for the unlikely $\mathrm{S}-\mathrm{R}$ ensemble than it was for the likely one. This pattern demonstrates, for the first time, that IOR has an interactive pattern with S-R probability, unlike the additivity seen with exogenous orienting (Kingstone \& Egly, 2001; Klein, 1994), and similar to the pattern that Klein and Hansen (1990) first observed with endogenous orienting. The implication of this finding, that IOR affects late response stages of processing, is illustrated in Figure 5 along with the effects of endogenous and exogenous attention on information processing as suggested by Klein (1994).

The interaction between S-R probability and IOR effects suggests that they share a common processing stage, but it should not be interpreted to mean that the IOR effect must be due to endogenous attention. Five lines of evidence converge against this explanation. First, Posner and Cohen (1984) demonstrated that central, predictive cues elicit endogenous shifts of attention, but they do not generate IOR. Second, Rafal et al. (1989) pointed out that canceling a shift of endogenous attention does not give rise to an IOR effect. Third, Posner and Cohen observed IOR even when the most likely target location was at the center and the uncued and cued locations were equiprobable. Fourth, Ivanoff and Klein (2003) found IOR when participants were unable to consciously localize the cue, suggesting that the IOR effect cannot be ascribed to a conscious or volitional mechanism. Lastly, Simion, Valenza, Umiltà, and Dalla (1995) observed IOR (measured with saccades) in newborns, who may be devoid of volitional control.

According to additive factors logic, an interaction between two factors is sufficient to demonstrate that they share a common processing stage - but further analysis is necessary to interpret the specific nature of the interaction. Chasteen and Pratt (1999) proposed, ad hoc, that the IOR effect will be larger when more information is being processed. If this were the case, then we should have observed larger IOR effect for the unlikely S-R ensemble than for the likely $\mathrm{S}-\mathrm{R}$ ensemble (which was clearly not observed). When viewed in the context of the rationale set forth by Klein and Hansen (1990), the results of the present experiments suggest that at the uncued location, there is a tendency to misclassify the unlikely stimulus and respond to it as if it were the likely one. In essence, there is a tendency to "expect" the likely target at the uncued location. In contrast, at the cued location, the criterion shift (due to IOR) mediates these misclassifications by allowing more information to accumulate. Such a criterion-setting locus for the interaction converges with Ivanoff and Klein's (2001) finding (replicated here) of fewer false alarms and slower responding at the cued location. Adopting this view in no way rules out the possibility of changes in processing efficiency 


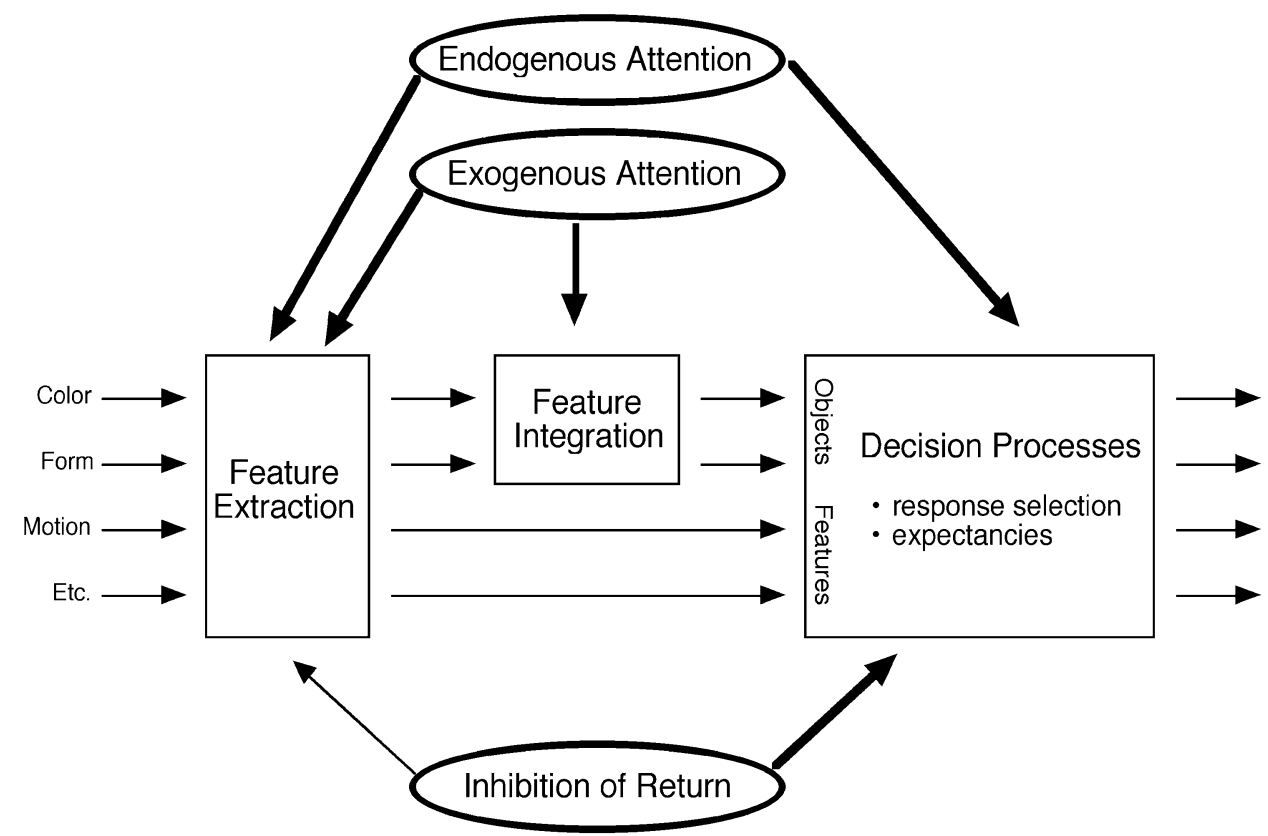

Figure 5. Stages alleged to be affected by endogenous attention, exogenous attention, and inhibition of return. This figure was adapted from Klein (1994).

(sensitivity) due to IOR. Indeed, Klein and Hansen noted that their findings could be simulated by assuming only criterion shifts or criterion shifts plus sensitivity changes due to endogenous covert orienting. They preferred an explanation in terms of both mechanisms, a choice that was subsequently supported by Handy et al. (2001). Similarly, our findings can be explained solely by criterion changes or by criterion changes together with sensitivity changes.

What is the status of IOR as a mechanism that inhibits perception and attention? Studies of IOR that have employed a simple RT task cannot readily measure accuracy. Thus, in a simple RT task, slowed RTs at the cued location may be ascribed to inhibited attention or to a raised criterion. The results from choice RT tasks are mixed in that some studies have reported more errors for targets at the cued location (e.g., Lupiáñez et al., 1997; Lupiáñez, Milliken, Solano, Weaver, \& Tipper, 2001) while others have failed to find this effect (Chasteen \& Pratt, 1999; Lupiáñez \& Milliken, 1999; Pratt et al., 1997). Direct attempts to measure accuracy (Cheal, Chastain, \& Lyon, 1998; Handy, Jha, \& Mangun, 1999; Klein \& Dick, 2002; McDonald, Ward \& Kiehl, 1999) provide converging evidence for the proposal that IOR decreases sensitivity. The problem with the methodologies adopted by these studies, however, is that in all but one $e^{4}$ the target was brief and/or masked. Under these conditions, a delayed response (i.e., a consequence of the criterion shift) combined with decaying evidence will result in slower RTs and less accurate performance (Posner, 1975). Thus, given the uncertain status of the inhibited attention account of IOR, in Figure 5 we have made the arrow reflecting the proposal that
IOR affects feature extraction thin to signify its tentative status.

Whether or not IOR reduces sensitivity in the kind of task we have employed does not diminish the important contribution of our experiments: The interaction between the IOR and $\mathrm{S}-\mathrm{R}$ probability effects suggests that, in one respect, the IOR effect is more similar to the effects of endogenous attention than to the effects of exogenous attention. More specifically, at a location "suffering" from IOR, not only do observers adopt a more conservative criterion, but the typical expectancy for the likely stimulus appears to be dampened.

\section{REFERENCES}

ARChibald, C. J. (1989). An electrophysiological study of the effects of location expectancy on reaction time and the visual sensory evoked potential. Unpublished master's thesis, Dalhousie University.

BRIAND, K. A. (1998). Feature integration and spatial attention: More evidence of a dissociation between endogenous and exogenous orienting. Journal of Experimental Psychology: Human Perception \& Performance, 24, 1243-1256.

BRIAND, K. A., \& KLEIN, R. M. (1987). Is Posner's "beam” the same as Treisman's "glue"? On the relation between visual orienting and feature integration theory. Journal of Experimental Psychology: Human Perception \& Performance, 13,228-241.

Chasteen, A. L., \& Pratt, J. (1999). The effect of inhibition of return on lexical access. Psychological Science, 10, 41-46.

Cheal, M. L., Chastain, G., \& Lyon, D. R. (1998). Inhibition of return in identification tasks. Visual Cognition, 5, 365-388.

Cheal, M. L., \& Lyon, D. R. (1991). Central and peripheral precuing of forced-choice discrimination. Quarterly Journal of Experimental Psychology, 43A, 859-880.

FitTs, P. M., \& PETERSON, J. (1964) . Information capacity of discrete motor responses. Journal of Experimental Psychology, 67, 103-112.

Folk, C. L., Remington, R., \& Johnston, J. C. (1992). Involuntary 
covert orienting is contingent on attentional control settings. Journal of Experimental Psychology: Human Perception \& Performance, 18, 1030-1044.

Handy, T. C., Green, V., Klein, R. M., \& Mangun, G. R. (2001). Combined expectancies: ERPs reveal early benefits of spatial attention that are absent in reaction time. Journal of Experimental Psychology: Human Perception \& Performance, 27, 303-317.

Handy, T. C., JHA, A. P., \& Mangun, G. R. (1999). Promoting novelty in vision: Inhibition of return modulates perceptual-level processing. Psychological Science, 10, 157-161.

HICK, W. E. (1952). On the rate of gain of information. Quarterly Journal of Experimental Psychology, 4, 11-26.

Hyman, R. (1953). Stimulus information as a determinant of reactiontime. Journal of Experimental Psychology, 45, 188-196.

Ivanoff, J., \& KleIn, R. M. (2001). The presence of a nonresponding effector increases inhibition of return. Psychonomic Bulletin \& Review, 8, 307-314.

IVANOFF, J., \& KLEIN, R. M. (2003). Orienting of attention without awareness is affected by measurement-induced attentional control settings. Journal of Vision, 3, 32-40.

JONIDES, J. (1981). Voluntary versus automatic control over the mind's eye's movement. In J. B. Long \& A. D. Baddeley (Eds.), Attention \& performance IX (pp. 187-203). Hillsdale, NJ: Erlbaum.

Kingstone, A., \& Egly, R. (2001). Attention to space and objects. Perception \& Psychophysics. Manuscript submitted for publication.

KLEIN, R. M. (1994). Perceptual-motor expectancies interact with covert visual orienting under conditions of endogenous but not exogneous control. Canadian Journal of Experimental Psychology, $\mathbf{4 8}$, 167-181.

KLEIN, R. M. (2000). Inhibition of return. Trends in Cognitive Sciences, 4, 138-147.

KLEIN, R. M., \& Dick, B. (2002). Temporal dynamics of reflexive attention shifts: A dual-stream rapid serial visual presentation exploration. Psychological Science, 13, 176-179.

KLEIN, R. M., \& HANSEN, E. (1990). Chronometric analysis of spotlight failure in endogenous visual orienting. Journal of Experimental Psychology: Human Perception \& Performance, 16, 790-801.

KLEIN, R. M., \& SHORE, D. I. (2000). Relations among modes of visual orienting. In S. Monsell \& J. Driver (Eds.), Attention and performance XVIII: Control of cognitive processes (pp. 195-208). Cambridge, MA: MIT Press.

KLEIN, R. M., \& TAYLOR, T. L. (1994). Categories of cognitive inhibition, with reference to attention. In D. Dagenbach \& T. H. Carr (Eds.), Inhibitory processes in attention, memory, and language (pp. 113150). San Diego: Academic Press.

LAMING, D. R. J. (1968). Information theory of choice-reaction times. New York: Academic Press.

Lu, Z.-L., \& Dosher, B. A. (2000). Spatial attention: Different mechanisms for central and peripheral temporal precues? Journal of Experimental Psychology: Human Perception \& Performance, 26, 15341548.

Lupiáñez, J., Milán, E. G., Tornay, F. J., Madrid, E., \& Tudela, P. (1997). Does IOR occur in discrimination tasks? Yes, it does, but later. Perception \& Psychophysics, 59, 1241-1254.

Lupiáñ EZ, J., \& MiLliKen, B. (1999). Inhibition of return and the attentional set for integrating versus differentiating information. Journal of General Psychology, 126, 392-418.

Lupiáñez, J., Milliken, B., SOlano, C., Weaver, B., \& Tipper, S. P. (2001). On the strategic modulation of the time course of facilitation and inhibition of return. Quarterly Journal of Experimental Psychology, 54A, 753-773.

MacPherson, A., Klein, R. M., \& Moore, C. (2003). Inhibition of return in children and adolescents. Journal of Experimental Child Psychology, 85, 337-351.

MATTES, S., Ulrich, R., \& Miller, J. O. (1997). Effects of response probability on response force in simple RT. Quarterly Journal of Experimental Psychology, 50A, 405-420.

Mattes, S., Ulrich, R., \& Miller, J. O. (2002). Response force in RT tasks: Isolating effects of stimulus probability and response probability. Visual Cognition, 9, 477-501.

McDonALD, J. J., WARD, L. M., \& KIEHL, K. A. (1999). An event-related brain potential study of inhibition of return. Perception \& Psychophysics, 61, 1411-1423.

Milán, E. G., \& ToRnAY, F. J. (2001). Spotlight failure effect in exogenous orienting. Acta Psychologica, 108, 209-218.

Miller, J. O. (1998). Effects of stimulus-response probability on choice reaction time: Evidence from the lateralized readiness potential. Journal of Experimental Psychology: Human Perception \& Performance, 24, 1521-1534.

PosNer, M. I. (1975). Psychobiology of attention. In M. Gazzaniga \& C. Blakemore (Eds.), Handbook of psychobiology (pp. 441-480). New York: Academic Press.

Posner, M. I. (1980). Orienting of attention. Quarterly Journal of Experimental Psychology, 32, 3-25.

Posner, M. I., \& CoHEN, Y. (1984). Components of visual orienting. In H. Bouma \& D. G. Bouwhuis (Eds.), Attention and performance X: Control of language processes (pp. 531-556). Hillsdale, NJ: Erlbaum.

Posner, M. I., Rafal, R. D., Choates, L. S., \& Vaughn, J. (1985). Inhibition of return: Neural basis and function. Cognitive Neuropsychology, 2, 211-228.

PrAtT, J., Kingstone, A., \& Khoe, W. (1997). Inhibition of return in location- and identity-based choice decision tasks. Perception \& Psychophysics, 59, 964-971.

Rafal, R. D., CaLABresi, P. A., Brennan, C. W., \& Sciolto, T. K. (1989). Saccade preparation inhibits reorienting to recently attended locations. Journal of Experimental Psychology: Human Perception \& Performance, 4, 673-685.

Simion, F., Valenza, E., Umiltà, C., \& Dalla, B. (1995). Inhibition of return in newborns is temporo-nasal asymmetrical. Infant Behavior \& Development, 8, 189-194.

STERnBERG, S. (1969). The discovery of processing stages: Extensions of Donders' method. Acta Psychologica, 30, 276-315.

TAYLOR, T. L., \& KLEIN, R. M. (1998). On the causes and effects of inhibition of return. Psychonomic Bulletin \& Review, 5, 625-643.

\section{NOTES}

1. The interaction observed with error rates was different from the interaction observed with RTs. When the likely S-R ensemble was present, there were fewer errors for cued (valid) than for uncued (invalid) targets. However, when the unlikely S-R ensemble was shown, there were more errors for cued (valid) than for uncued (invalid) targets. Klein and Hansen (1990) suggested that the combined pattern with errors and RTs indicates that the criterion for likely targets at the cued (valid) location is lower than the criterion for likely targets at the uncued (invalid) location.

2. Milán and Tornay (2001) recently observed that the effects of exogenous orienting and S-R probability interact with RTs, but not with error rates. In a recent (unpublished) attempt to replicate Milán and Tornay's finding, using a methodology that closely matches theirs, we found additivity with both measures when RTs beyond $1 \mathrm{sec}$ were eliminated from further analysis. Thus, we think that it is plausible that Milán and Tornay's finding is due to their inclusion of extremely long RTs in their analysis.

3. Briand (1998) and Briand and Klein (1987) have provided a complementary dissociation between exogenous and endogenous orienting. They observed that the opportunity for illusory conjunctions within a stimulus set interacted with the effects of exogenous, but not endogenous, orienting. With the findings of Klein (1994), this offers evidence of a behavioral double dissociation between exogenous and endogenous orienting (Klein \& Shore, 2000).

4. Only McDonald et al. (1999) did not mask the target and their target's presence was not brief. However, their evidence for reduced sensitivity is indirectly derived from early features (i.e., P1) of event-related potentials (ERPs). Whether the ERP cuing differences truly reflect reduced perception will require direct effects on measures of perception (e.g., $d^{\prime}$ or percent correct). 
Table A1

Mean RTs (in Milliseconds) and Percent Errors (in Parentheses) for Each Level of Cuing, Target Likelihood, and Cue-Target Onset Asynchrony (CTOA) for Experiments 1 and 2

\begin{tabular}{|c|c|c|c|c|c|c|}
\hline & \multicolumn{6}{|c|}{ CTOA } \\
\hline & \multicolumn{2}{|c|}{$150 \mathrm{msec}$} & \multicolumn{2}{|c|}{$465 \mathrm{msec}$} & \multicolumn{2}{|c|}{$1,050 \mathrm{msec}$} \\
\hline & Cued & Uncued & Cued & Uncued & Cued & Uncued \\
\hline \multicolumn{7}{|l|}{ Experiment 1} \\
\hline $\begin{array}{l}\text { Go target likely } \\
\text { (No-go target unlikely) } \\
\text { Go target unlikely } \\
\text { (No-go target likely) }\end{array}$ & & & $\begin{array}{c}386 \\
(3.89) \\
407 \\
(0.37)\end{array}$ & $\begin{array}{c}344 \\
(10.56) \\
382 \\
(2.41)\end{array}$ & $\begin{array}{c}369 \\
(2.78) \\
386 \\
(0.19)\end{array}$ & $\begin{array}{c}335 \\
(15.56) \\
371 \\
(1.48)\end{array}$ \\
\hline \multicolumn{7}{|l|}{ Experiment 2} \\
\hline Likely target & $\begin{array}{c}476 \\
(2.08)\end{array}$ & $\begin{array}{c}445 \\
(1.54)\end{array}$ & $\begin{array}{c}427 \\
(1.64)\end{array}$ & $\begin{array}{c}397 \\
(1.64)\end{array}$ & $\begin{array}{c}396 \\
(2.74)\end{array}$ & $\begin{array}{c}379 \\
(1.54)\end{array}$ \\
\hline Unlikely target & $\begin{array}{c}525 \\
(7.57)\end{array}$ & $\begin{array}{c}510 \\
(10.86)\end{array}$ & $\begin{array}{c}495 \\
(7.57)\end{array}$ & $\begin{array}{c}485 \\
(16.45)\end{array}$ & $\begin{array}{c}467 \\
(9.87)\end{array}$ & $\begin{array}{c}456 \\
(13.49)\end{array}$ \\
\hline
\end{tabular}

Note-In Experiment 1, an error is a false alarm (i.e., a response to the no-go target). A false alarm in the block of trials in which the go target is likely is a response to the unlikely no-go target. Likewise, false alarms are responses to the likely no-go target in the block of trials in which the go target is unlikely. In Experiment 2, an error is an incorrect keypress response.

(Manuscript received January 29, 2003;)

revision accepted for publication August 7, 2003.) 